\title{
Metamictization of zircon: Raman spectroscopic study
}

\author{
Ming Zhang $\dagger$, Ekhard K H Salje $\dagger$, Ian Farnan $\dagger$, Ann Graeme-Barber $\dagger$, \\ Philippe Daniel $\$$, Rodney C Ewing§, Andrew M Clark $\|$ and Hugues Leroux $\uparrow$ \\ $\dagger$ Department of Earth Sciences, University of Cambridge, Downing Street, \\ Cambridge CB2 3EQ, UK \\ \$ Laboratoire de Physique de l'Etat Condensé, UPRES A CNRS No 6087, \\ Université du Maine-Faculté des Sciences, Avenue Olivier Messiaen, 72085 Le Mans Cédex 9, \\ France \\ $\S$ Department of Nuclear Engineering and Radiological Sciences, \\ Department of Geological Sciences, University of Michigan, Ann Arbor, MI 48109-2104, USA \\ || Department of Mineralogy, Natural History Museum, Cromwell Road, London, SW7 5BD, UK \\ I Laboratoire de Structure et Propriétés de l'Etat Solide, Batiment C6, \\ Universite Sciences et Technologies de Lille, 59655 Villeneuve d'Ascq, France \\ E-mail: mz10001@esc.cam.ac.uk (M Zhang)
}

Received 30 June 1999, in final form 13 December 1999

\begin{abstract}
Raman spectroscopy of radiation-damaged natural zircon samples shows increased line broadening and shifts of phonon frequencies with increasing radiation dose. Stretching and bending frequencies of $\mathrm{SiO}_{4}$ tetrahedra soften dramatically with increasing radiation damage. The frequency shifts can be used to determine the degree of radiation damage. Broad spectral bands related to $\mathrm{Si}-\mathrm{O}$ stretching vibrations between 900 and $1000 \mathrm{~cm}^{-1}$ were observed in metamict/amorphous zircon. The radiation-dose-independent spectral profiles and the coexistence of this broad background and relative sharp Raman modes in partially damaged samples indicate that these bands are correlated with amorphous domains in zircon. The spectral profiles of metamict zircon suggest that in comparison with silica, the $\mathrm{SiO}_{4}$ tetrahedra are less polymerized in metamict zircon. This study also shows that $\mathrm{ZrO}_{2}$ and $\mathrm{SiO}_{2}$ are not the principal products of metamictization in zircon. No indication of bulk chemical unmixing of zircon into $\mathrm{ZrO}_{2}$ and $\mathrm{SiO}_{2}$ was found in 26 samples with a large variation of radiation damage (maximum dose: $23.5 \times 10^{18} \alpha$-events $\mathrm{g}^{-1}$ ). Only one sample showed clearly, in all measured sample areas, extra sharp lines at 146, 260,312, 460 and $642 \mathrm{~cm}^{-1}$ characteristic of tetragonal $\mathrm{ZrO}_{2}$. The geological (and possibly artificial heating) history of this sample is not known. It is concluded that radiation damage without subsequent high temperature annealing does not cause unmixing of zircon into constituent oxides.
\end{abstract}

\section{Introduction}

Zircon $\left(\mathrm{ZrSiO}_{4}\right)$ is tetragonal: $I 4_{1} /$ amd and $Z=4$ (Hazen and Finger 1979). The ideal structure consists of a chain of alternating, edge-sharing $\mathrm{SiO}_{4}$ tetrahedra and $\mathrm{ZrO}_{8}$ triangular dodecahedra extending parallel to crystallographic axis $c$. Natural zircon commonly contains $\mathrm{U}$ and Th as well as other rare earth elements. Due to radioactive decay of naturally occurring radionuclides, and their daughter products in the ${ }^{238} \mathrm{U},{ }^{235} \mathrm{U}$ and ${ }^{232} \mathrm{Th}$ decay series, the structure of zircon can be heavily damaged by $\alpha$-decay events (Weber et al 1997). As a result, natural zircon is commonly found to be 'metamict', an aperiodic or amorphous state (Ewing 1994). Radiation effects in zircon have important implications in several application fields. Zircon has been proposed as a host phase for the disposal of excess weapons-grade $\mathrm{Pu}$ and other actinides (Burakov 1993, Anderson et al 1993, Ewing et al 1995, Weber et al 1996, Ewing 1999). 
Self-radiation damage from $\alpha$-decay of the incorporated actinides can affect the durability and performance of these actinide-bearing phases. The evaluation of the effect of radiation on the crystalline phase and an understanding of the damage mechanism and the structure of the damaged phase have been one of the critical concerns in this application on actinide waste form.

The effects of radiation damage on the structure of zircon can be seen as systematic changes of its physical properties: an increase in cell parameters and broadening of x-ray diffraction patterns (Holland and Gottfried 1955, Murakami et al 1991, Weber 1993); a decrease in IR and Raman intensities and dramatic band broadening (Vance 1975, Woodhead et al 1991a, Nasdala et al 1995, 1996, 1998); decreases in refractive index and birefringence (Holland and Gottfried 1955, Vance and Anderson 1972); absorption of hydrous species (Aines and Rossman 1986 and Woodhead et al 1991b); an increase in fracture toughness (Chakoumakos et al 1987); a decrease in density (Holland and Gottfried 1955, Murakami et al 1991); a variation of HRTEM diffraction patterns (Yada et al 1987, Murakami et al 1991); a variation of ${ }^{29} \mathrm{Si}$ NMR features (Farnan et al 1999); decreases in hardness and bulk modulus (Chakoumakos et al 1991); a variation of diffuse x-ray scattering from single crystals (Salje et al 1999) and the appearance of Huang type diffuse x-ray diffraction (Ríos and Salje 1999).

Despite extensive studies on metamict zircon, controversies concerning the structure of metamict zircon remain. In their x-ray and optical investigation, Holland and Gottfried (1955) observed in their $\mathrm{x}$-ray data a systematic development and disappearance of an extra peak near $2 \theta$ of $35-36.5^{\circ}$ with increasing degree of $\alpha$-decay radiation damage. They proposed the formation of an intermediate polycrystalline phase with intermediate dose. In an x-ray study by Murakami et al (1991), peak splitting was observed for most of the partially damaged samples, and this was interpreted as the coexistence of two phases with different degrees of damage. There have been reports of the presence of crystalline $\mathrm{ZrO}_{2}$ in metamict zircon. Stott and Hilliard (1946) reported that an unheated sample gave an x-ray pattern of monoclinic $\mathrm{ZrO}_{2}$, while cubic and probably tetragonal $\mathrm{ZrO}_{2}$ have been reported in different studies (Anderson 1962, Vance and Anderson 1972). In their infrared spectroscopic work Wasilewski et al (1973) analysed their data in terms of a two-stage damage process. In the first stage the effect of $\alpha$-recoil damage on undamaged zircon is claimed to produce, throughout the lattice, highly stressed and expanded zircon with distorted $\mathrm{SiO}_{4}$ tetrahedra, while in the second stage the recoil nucleus is thought to cause the formation of $\mathrm{ZrO}_{2}, \mathrm{SiO}_{2}$ and probably some aperiodic $\mathrm{ZrSiO}_{4}$. A study by Vance (1975) indicated that the $\mathrm{Si}-\mathrm{O}$ bonding in heavily damaged zircon was not too different from that in glassy $\mathrm{SiO}_{2}$, as infrared spectra of $\mathrm{Si}-\mathrm{O}$ vibrations in heavily damaged zircon were similar to that of vitreous $\mathrm{SiO}_{2}$. The presence of crystalline $\mathrm{ZrO}_{2}$ was observed in heavily damaged zircon annealed at high temperatures (Ellsworth et al 1994, McLaren et al 1994). Recently Meldrum et al (1998, 1999b) reported an observation of decomposition of synthetic zircon under high-temperature heavy-ion irradiation and proposed the formation of a 'liquid-like' state in displacement cascades and that a low cooling rate could allow the nucleation of crystalline $\mathrm{ZrO}_{2}$ in displacement cascade regions. It has also been reported that several important similarities and differences exist among ion-irradiated specimens and minerals that undergo radiation damage from $\alpha$-decay processes (Meldrum et al 1999a). In an X-ray absorption spectroscopic study at the $\mathrm{Zr}-\mathrm{K}$ edge, Farges and Calas (1991) saw no evidence for decomposition into crystalline oxides in metamict zircon and reported a decrease in $\mathrm{Zr}-\mathrm{O}$ distance of $0.1 \AA$ while the coordination number of $\mathrm{Zr}$ decreased from eight to seven. An infrared study by Woodhead et al (1991a) reported that the structure of metamict zircon consisted of distorted and disoriented isolated silica tetrahedra with few if any undisplaced $\mathrm{Zr}$ cations. Raman work by Nasdala et al (1995) showed no indication of an amorphous phase as very heavily damaged samples still gave rise to relatively sharp 
lines. Their results did not support an increasing polymerization of $\mathrm{SiO}_{4}$ tetrahedra with increasing dose and they considered that isolated $\mathrm{SiO}_{4}$ tetrahedra were distorted and tilted with increasing degree of damage but still isolated in a highly metamict state. Salje et al (1999) showed recently that metamictization in zircon could not be a phase transition driven by a critical defect concentration, but rather was a heterogeneous process of cascade formation and overlap. Instead of a 'driven phase transition' two percolation points are expected, one for the crystalline material and one for the amorphous material.

We undertook this Raman investigation of radiation-damaged zircon in order to study possible variations of local environments, the nature of the polymerization and whether metamict zircon mainly consists of $\mathrm{ZrO}_{2}$ and $\mathrm{SiO}_{2}$.

\section{Experiment}

\subsection{Sample description}

Zircon samples used in this study are all gemstones from Sri Lanka. The Sri Lanka zircons were selected because of their low impurities, low $\mathrm{OH}$ content, different degree of radiation damage, gem quality and well defined geological age ( $570 \pm 20$ million years). Among these samples twelve have been used in previous studies by Murakami et al (1991) and Ellsworth et al (1994). Other samples were characterized by electron microprobe, reflection and absorption infrared spectroscopy, x-ray diffraction and NMR. The chemical analysis has shown that the total content of impurities in any sample was less than $3 \mathrm{~mol} \%$ and the most significant impurities are $\mathrm{Hf}, \mathrm{U}, \mathrm{Th}$ and $\mathrm{Y}$. The content of individual impurities varies from sample to sample. However, for all the samples the Hf content is less than $2.5 \mathrm{~mol} \%, \mathrm{Al}<0.1 \mathrm{~mol} \%$, $\mathrm{Th}<0.8 \mathrm{~mol} \%, \mathrm{U}<1.4 \mathrm{~mol} \%$ and $\mathrm{Y}<0.2 \mathrm{~mol} \%$. The lattice parameters of some samples were determined by x-ray Guinier powder diffraction with $\mathrm{Si}$ as internal standard. More detailed information on the samples is listed in tables 1 and 2 .

Thermal annealing of sample 4604 was carried out between $600 \mathrm{~K}$ and $1700 \mathrm{~K}$ by step heating for one hour at each chosen temperature under $\mathrm{N}_{2}$ flow. The samples were quenched to room temperature after each anneal.

\subsection{Raman measurement}

Raman spectra were recorded with a DILOR Z24 spectrometer triple monochromator in a single channel mode, coupled to a Coherent 90-3 argon ion laser. The selected incident wavelengths were 514, 488 and $457 \mathrm{~nm}$ in order to clearly identify the luminescence bands due to low concentration impurities. The microscope configuration was used (magnification objective $50 \times$ ). Slit widths were adjusted to obtain an $8 \mathrm{~cm}^{-1}$ spectral line width. In each experiment 15 scans were collected and averaged.

FT-Raman spectra were recorded at room temperature using a Bruker IFS 66v spectrometer adapted with a Bruker FRA 106 FT-Raman accessory. A silicon-coated calcium fluoride beamsplitter and radiation of $1064 \mathrm{~nm}$ from an Nd:YAG laser was used for the excitation laser which can produce $350 \mathrm{~mW}$ output. A liquid-nitrogen-cooled high sensitivity Ge detector was used. The spectra were recorded with a laser power of $45-100 \mathrm{~mW}$ and a back-scattering geometry. The focused beam was about $200 \mu \mathrm{m}$ in size. For crystalline zircons 250-512 scans were used and 1000-3000 scans for heavily damaged zircons. The resolution of all the spectra was $2 \mathrm{~cm}^{-1}$.

Laser power was carefully chosen to avoid potential damage to the measured areas caused by the intense local heat from the laser beam. Various laser powers were used in order to test the 
Table 1. Zircon sample descriptions. Density is in units of $\mathrm{g} \mathrm{cm}^{-3}$ and dosage in units of $10^{18} \alpha$-events $\mathrm{g}^{-1}$.

\begin{tabular}{|c|c|c|c|c|c|c|c|}
\hline Zircon & Locality & Density & dosage & $a(\AA)$ & $c(\AA)$ & $V\left(\AA^{3}\right)$ & Reference/source \\
\hline $4403^{\mathrm{a}}$ & Sri Lanka & 4.72 & 0.06 & 6.6085 & 5.9845 & 261.36 & Murakami et al (1991), Ellsworth et al (1994) \\
\hline Fumt10 & Sri Lanka & ND & 0.5 & 6.6046 & 5.9810 & 260.90 & FUMT \\
\hline $3104^{\mathrm{b}}$ & Sri Lanka & 4.68 & 1.0 & & ND & & Ellsworth et al (1994) \\
\hline S3 & Sri Lanka & ND & 0.8 & 6.6135 & 5.9990 & 262.39 & CAM \\
\hline 269 & Sri Lanka & ND & 1.8 & 6.6301 & 6.0266 & 264.91 & NHM \\
\hline $4605^{\mathrm{a}}$ & Sri Lanka & 4.58 & 2.0 & 6.645 & 6.047 & 267.01 & Murakami et al (1991) \\
\hline $4303^{\mathrm{a}}$ & Sri Lanka & 4.58 & 2.1 & 6.652 & 6.051 & 267.8 & Murakami et al (1991), Ellsworth et al (1994) \\
\hline 4694 & Sri Lanka & 4.57 & 2.8 & 6.645 & 6.042 & 266.8 & CAM \\
\hline Cam26 & Sri Lanka & ND & 2.9 & & ND & & CAM \\
\hline $4604^{\mathrm{a}}$ & Sri Lanka & 4.54 & 3.5 & 6.68 & 6.07 & 271 & Murakami et al (1991) \\
\hline $\mathrm{Z} 5$ & Sri Lanka & 4.36 & 4.2 & & ND & & HAM \\
\hline S4 & Sri Lanka & ND & 4.8 & 6.67 & 6.09 & 271 & CAM \\
\hline Cam25 & Sri Lanka & ND & 5.2 & & ND & & CAM \\
\hline $4304^{\mathrm{a}}$ & Sri Lanka & 4.36 & 5.8 & 6.67 & 6.13 & 273 & Murakami et al (1991) \\
\hline $4103^{\mathrm{a}}$ & Sri Lanka & 4.17 & 6.7 & 6.70 & 6.15 & 276 & Murakami et al (1991) \\
\hline $\mathrm{Cam} 27$ & Sri Lanka & ND & 5.6 & & ND & & CAM \\
\hline $4105^{\mathrm{a}}$ & Sri Lanka & 4.25 & 6.3 & 6.70 & 6.13 & 275 & Murakami et al (1991), Ellsworth et al (1994) \\
\hline Ni12 & Sri Lanka & 4.2 & 7.1 & & ND & & HAM \\
\hline $3107^{\mathrm{b}}$ & Sri Lanka & 4.12 & 7.2 & & ND & & Ellsworth et al (1994) \\
\hline $\mathrm{Z} 2$ & Sri Lanka & 4.03 & 8.6 & & ND & & HAM \\
\hline Ti8 & Sri Lanka & 4.04 & 9.6 & unable & e to deter & rmine $a$ and $c$ & HAM \\
\hline $6500^{c}$ & Sri Lanka & ND & 11.7 & unable & e to deter & rmine $a$ and $c$ & Woodhead et al (1991a) \\
\hline 157 & Sri Lanka & 3.96 & 13.1 & & ND & & NHM \\
\hline $\mathrm{Sd} 4$ & Sri Lanka & ND & 15.9 & & ND & & CAM \\
\hline 82988 & Sri Lanka & ND & 23.5 & & ND & & NHM \\
\hline Cam1 & unknown & ND & ND & 6.6070 & 6.0221 & 262.88 & CAM \\
\hline
\end{tabular}

${ }^{a}$ Measured by Murakami et al (1991)

${ }^{\mathrm{b}}$ Measured by Ellsworth et al (1994).

${ }^{\mathrm{c}}$ Measured by Woodhead et al (1991a).

$\mathrm{ND}=$ not determined.

$\mathrm{CAM}=$ Sedgewick Museum, University of Cambridge, UK;

FUMT $=$ Freiberg University of Mining and Technology, Germany;

HAM = Mineralogisches Museum, Mineralogisch-Petrographisches, Universität Hamburg, Germany;

$\mathrm{NHM}=$ Natural History Museum, UK.

The original British Museum Catalogue numbers for the samples from NHM are: $269=$ BM1920, 269; $157=$ BM1921, 157; and $82988=$ BM82988.

hypothesis that intensive laser heating could lead to unwanted annealing of radiation damage. No such effects were observed. The time dependence of FT-Raman spectrum for sample 269 and Ni12 was also examined to check whether the samples were overheated. After 2 hours of irradiation at a power of $200 \mathrm{~mW}$ with a beam size of $\sim 200 \mu \mathrm{m}$, the spectra remained unchanged. Samples were checked after Raman measurements using an optical microscope. No indications of surface damage and change of colour by the laser radiation were observed.

\section{Results}

Theoretical analysis (Dawson et al 1971) predicts twelve Raman-active normal modes in zircon at $k=0: 2 \mathrm{~A}_{1 g}+4 \mathrm{~B}_{1 g}+\mathrm{B}_{2 g}+5 \mathrm{E}_{g}$. Raman zone-centre normal modes can also be 
Table 2. Electron microprobe analyses of zircon samples that have not been characterized in previous studies.

\begin{tabular}{lllllllllll}
\hline Sample & $\mathrm{SiO}_{2}$ & $\mathrm{FeO}$ & $\mathrm{ZrO}_{2}$ & $\mathrm{HfO}_{2}$ & $\mathrm{CaO}$ & $\mathrm{Al}_{2} \mathrm{O}_{3}$ & $\mathrm{Y}_{2} \mathrm{O}_{3}$ & $\mathrm{ThO}_{2}$ & $\mathrm{UO}_{2}$ & Total \\
\hline Fumt10 & 33.01 & - & 65.85 & 0.81 & 0.01 & - & 0.14 & 0.01 & 0.03 & 99.86 \\
$\mathrm{~S} 3$ & 33.41 & - & 64.61 & 1.48 & 0.01 & - & 0.06 & 0.03 & 0.04 & 99.64 \\
4605 & 32.16 & 0.04 & 67.03 & 1.23 & - & - & 0.07 & 0.05 & 0.21 & 100.79 \\
4694 & 32.95 & 0.06 & 64.11 & 1.65 & - & 0.01 & 0.19 & 0.08 & 0.19 & 99.24 \\
$\mathrm{Cam} 26$ & 33.36 & 0.01 & 65.26 & 1.28 & 0.01 & - & 0.03 & 0.03 & 0.18 & 100.16 \\
4604 & 32.04 & 0.02 & 66.51 & 1.27 & - & - & 0.10 & 0.08 & 0.32 & 100.34 \\
$\mathrm{Z5}$ & 33.55 & - & 65.07 & 1.85 & - & 0.01 & 0.01 & 0.01 & 0.29 & 100.79 \\
$\mathrm{~S} 4$ & 33.38 & - & 65.15 & 0.99 & - & 0.01 & 0.05 & 0.11 & 0.23 & 99.92 \\
$\mathrm{Cam} 25$ & 33.26 & - & 63.74 & 1.77 & - & - & 0.22 & 0.07 & 0.31 & 99.37 \\
$\mathrm{Cam} 27$ & 33.38 & - & 63.26 & 2.81 & 0.01 & - & 0.22 & 0.05 & 0.36 & 100.09 \\
$\mathrm{Ni} 12$ & 32.68 & - & 65.74 & 1.64 & - & 0.01 & 0.02 & 0.14 & 0.39 & 100.62 \\
$\mathrm{Z} 2$ & 33.46 & - & 65.17 & 1.19 & - & - & 0.07 & 0.07 & 0.46 & 100.49 \\
Ti8 & 32.77 & 0.01 & 64.01 & 2.56 & 0.01 & 0.13 & 0.03 & 0.05 & 0.55 & 100.29 \\
157 & 32.48 & 0.01 & 64.85 & 2.36 & 0.05 & - & 0.10 & 0.08 & 0.86 & 100.79 \\
Sd4 & 32.69 & 0.01 & 65.66 & 0.63 & - & 0.01 & 0.01 & 0.12 & 1.02 & 100.15 \\
82988 & 32.91 & 0.01 & 63.08 & 1.80 & - & - & 0.47 & 0.30 & 1.38 & 99.95 \\
\hline
\end{tabular}

- undetectable.

described as internal modes and external modes: internal $=2 \mathrm{~A}_{1 g}+2 \mathrm{~B}_{1 g}+\mathrm{B}_{2 g}+2 \mathrm{E}_{g}$ while external $=2 \mathrm{~B}_{1 g}$ (translatory) $+2 \mathrm{E}_{g}$ (translatory) $+\mathrm{E}_{g}$ (rotatory) .

Raman spectra of natural zircon show systematic variations with increasing degree of metamictization (figure 1). Nine of the 12 predicted Raman modes were observed in the most crystalline zircon 4403 (figure 1). They are internal modes: $1008 \mathrm{~cm}^{-1}\left(\mathrm{~B}_{1 g}, \mathrm{Si}-\mathrm{O}\right.$ $\nu_{3}$ stretching), $975 \mathrm{~cm}^{-1}\left(\mathrm{~A}_{1 g}, \mathrm{Si}-\mathrm{O} v_{1}\right.$ stretching $), 439 \mathrm{~cm}^{-1}\left(\mathrm{~A}_{1 g}, \mathrm{Si}-\mathrm{O} v_{2}\right.$ bending $)$ and $269 \mathrm{~cm}^{-1}\left(\mathrm{~B}_{2 g}, \mathrm{Si}-\mathrm{O} v_{2}\right.$ bending) and external modes: 393, 355, 225, 214 and $202 \mathrm{~cm}^{-1}$ (Syme et al 1977, Hoskin and Rodgers 1996). The other predicted bands are probably too weak to be observed in our experimental set-up.

The effects of $\alpha$-decay radiation damage on the structure of zircon are characterized by a decrease in Raman intensity, a decrease in phonon frequencies and line-broadening of Raman modes. Well crystallized zircon samples show sharp and well resolved Raman modes (figure 1(a) and 1(b)). With increasing $\alpha$-decay radiation dose, the two $\mathrm{Si}-\mathrm{O}$ stretching modes between 970 and $1010 \mathrm{~cm}^{-1}$ become weaker and broader while the lower-frequency modes become gradually weak and could not be analysed for high dose. These spectral variations are accompanied by a development of a broad spectral feature between 850 and $1100 \mathrm{~cm}^{-1}$ which can be clearly seen in heavily damaged samples (figure 1(c)). As this broad feature appears in both FT-Raman and conventional Raman spectra, we conclude that this feature is not related to impurity luminescence but seems due to the amorphous phase in damaged zircon samples.

We now analyse the spectra in terms of a simple two-phase behaviour. Phonon frequencies of crystalline/distorted crystalline zircon show a systematic variation with radiation damage (figure 2). With increasing damage, the frequencies of the $\mathrm{Si}-\mathrm{O}$ stretching mode near $1008 \mathrm{~cm}^{-1}$ and the external vibration near $356 \mathrm{~cm}^{-1}$ decrease strongly at doses below $3.5 \times 10^{18} \alpha$-events $\mathrm{g}^{-1}$ and saturate at higher doses. The frequency decrease is $\sim 1.5 \%$ for the $\mathrm{Si}-\mathrm{O}$ stretching mode at $1008 \mathrm{~cm}^{-1}, \sim 1.0 \%$ for the $\mathrm{Si}-\mathrm{O}$ stretching at $975 \mathrm{~cm}^{-1}$, $\sim 0.8 \%$ for the $\mathrm{Si}-\mathrm{O}$ bending near $438 \mathrm{~cm}^{-1}$ and $\sim 2.8 \%$ for the external mode at $355 \mathrm{~cm}^{-1}$ which is related to the motion of $\mathrm{SiO}_{4}$ as a unit against $\mathrm{Zr}$. The frequency shift for the external bands below $250 \mathrm{~cm}^{-1}$ is difficult to determine as their intensities and shift in frequency are too weak to allow reliable measurements. 


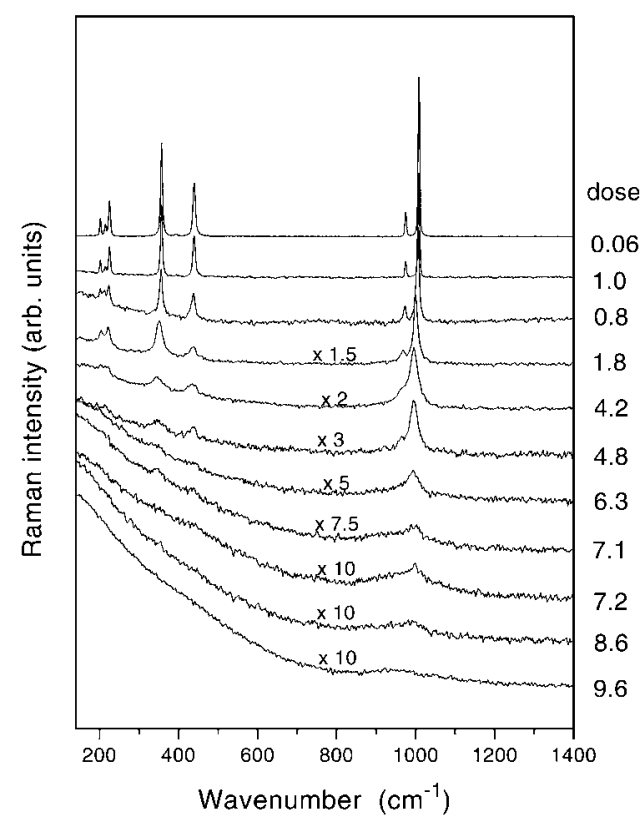

(a)

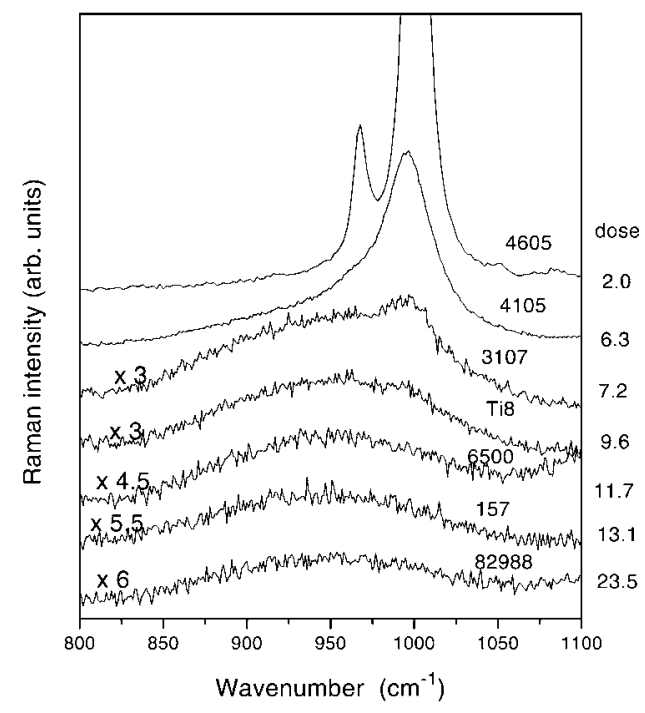

(c)

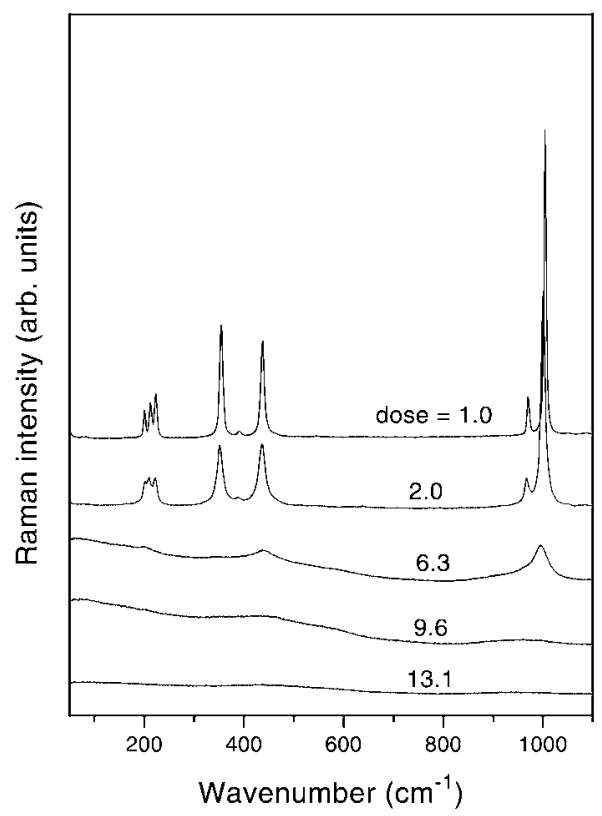

(b)

Figure 1. Raman spectra of zircon. (a) FT-Raman spectra (with $1064 \mathrm{~nm}$ excitation) between 140 and $1400 \mathrm{~cm}^{-1}$; (b) conventional Raman spectra (with $488 \mathrm{~nm}$ excitation) between 100 and $1100 \mathrm{~cm}^{-1}$; (c) enlarged spectra between 800 and $1100 \mathrm{~cm}^{-1}$ (488 nm excitation) to show details of spectra of amorphous phase. Radiation dosage is in units of $10^{18} \alpha$-events $\mathrm{g}^{-1}$. The low-wavenumber spectral differences between FT-Raman and conventional Raman spectra in heavily damaged samples could be due to luminescence and the difference of sensitivity between FT and conventional Raman spectroscopy.

Within experimental resolution, no clear band-splitting and no extra signals were observed that could indicate a change of symmetry of crystalline material in partially metamict zircon. Although x-ray data for the samples show a similar peak splitting for $2 \theta$ between 35 and $37^{\circ}$ observed by Holland and Gottfried (1955), this splitting in $2 \theta$ is likely due to co-existence of areas with different degrees of damage rather than a structural phase transition as explained by Murakami et al (1991).

In the following we focus on spectral features related to the amorphous phase. The coexistence of the broad feature between 850 and $1100 \mathrm{~cm}^{-1}$ and the Si-O stretching band near $995 \mathrm{~cm}^{-1}$ in the same spectral region in samples 4105 and 3107 indicates the coexistence of 


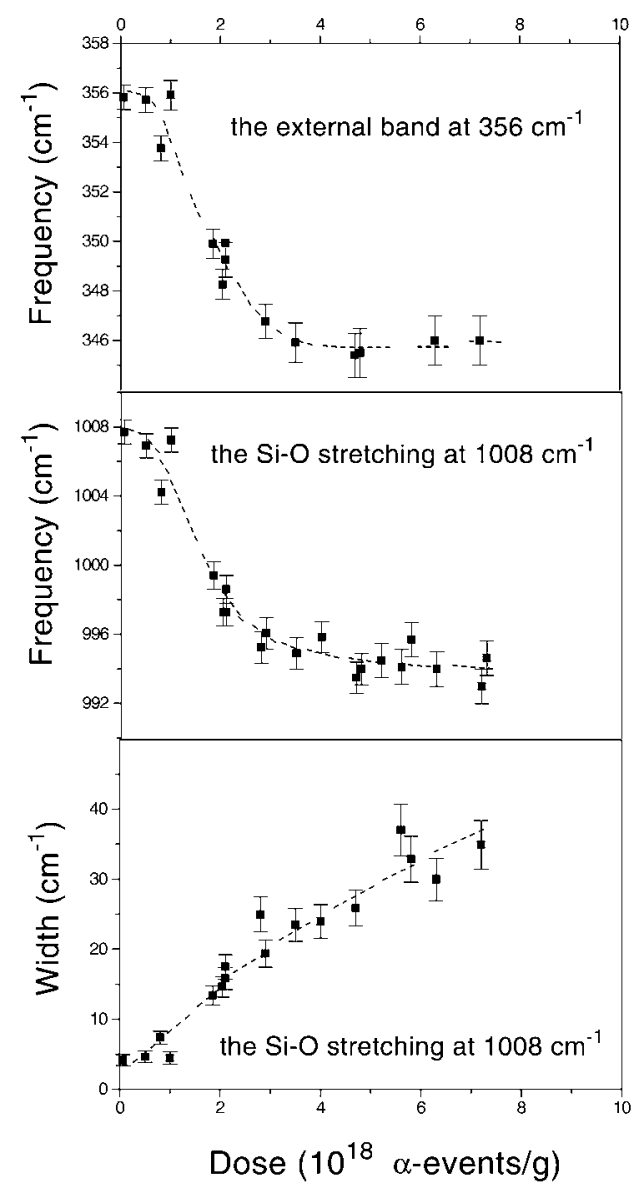

Figure 2. Phonon frequencies and width as a function of radiation dose (each point is an average of six measurements). The lines are visual guides.

the amorphous phase and damaged crystalline material (figure 1(c)). The gradual development of this background shows the accumulation of the amorphized phase with increasing radiation dose. A spectral subtraction was performed to remove the signals of the amorphized phase (sample 82988) from the measured spectra (figure 3). The comparison of the broad bands in samples 4105 and 3107 suggests that the structure of the amorphous phase is essentially identical when dose is higher than $6.3 \times 10^{18} \alpha$-events $\mathrm{g}^{-1}$. Deconvolution of the spectra between 750 and $1100 \mathrm{~cm}^{-1}$ shows that the spectrum of the amorphous phase in this region consists of two main vibrations located at $920 \pm 15 \mathrm{~cm}^{-1}$ and $970 \pm 20 \mathrm{~cm}^{-1}$. Their positions and spectral features do not show a clear dose dependence. Due to its low Raman intensity this broad feature can be hardly traced in slightly or partially damaged samples with dose less than $3 \times 10^{18} \alpha$-events $\mathrm{g}^{-1}$. The identical spectral features for the samples with dose higher than $10\left(10^{18} \alpha\right.$-events $\left.\mathrm{g}^{-1}\right)$ indicates that further bombardment of the amorphous phase by $\alpha$-particles does not lead to further significant changes of the structure of metamict zircon.

Among all samples studied only one sample, Cam1, shows Raman bands of zircon plus additional sharp lines at 146, 260,312, 460 and $642 \mathrm{~cm}^{-1}$ which are indicative of crystalline 


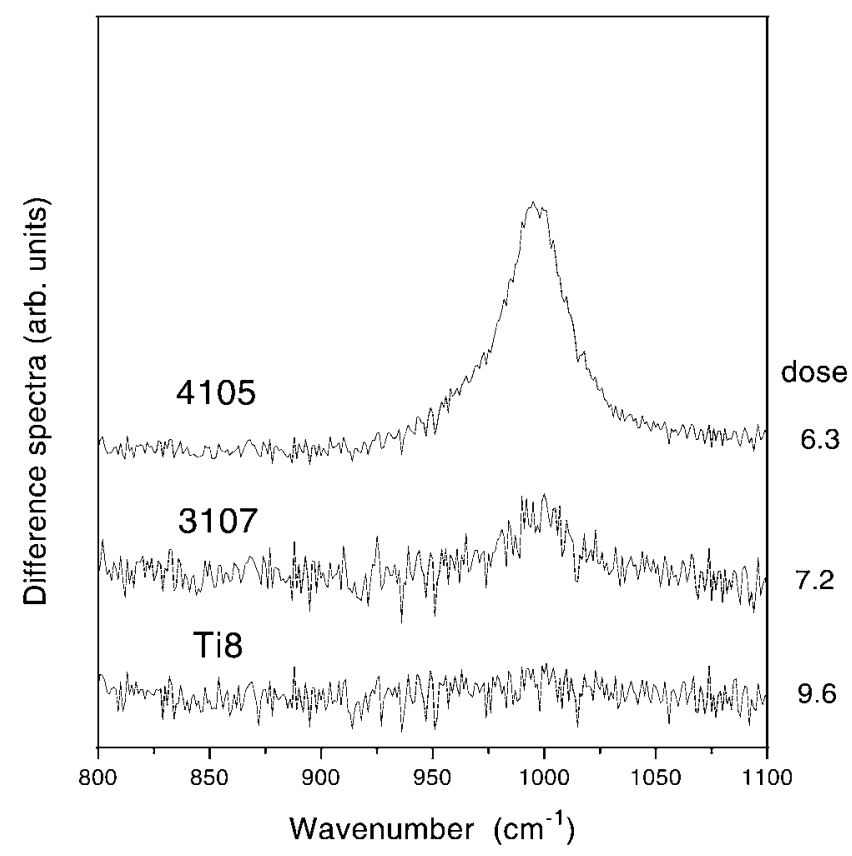

Figure 3. Difference spectra of samples 4105, 3107 and Ti8 after spectrum subtraction. Radiation dosage is in units of $10^{18} \alpha$-events $\mathrm{g}^{-1}$.

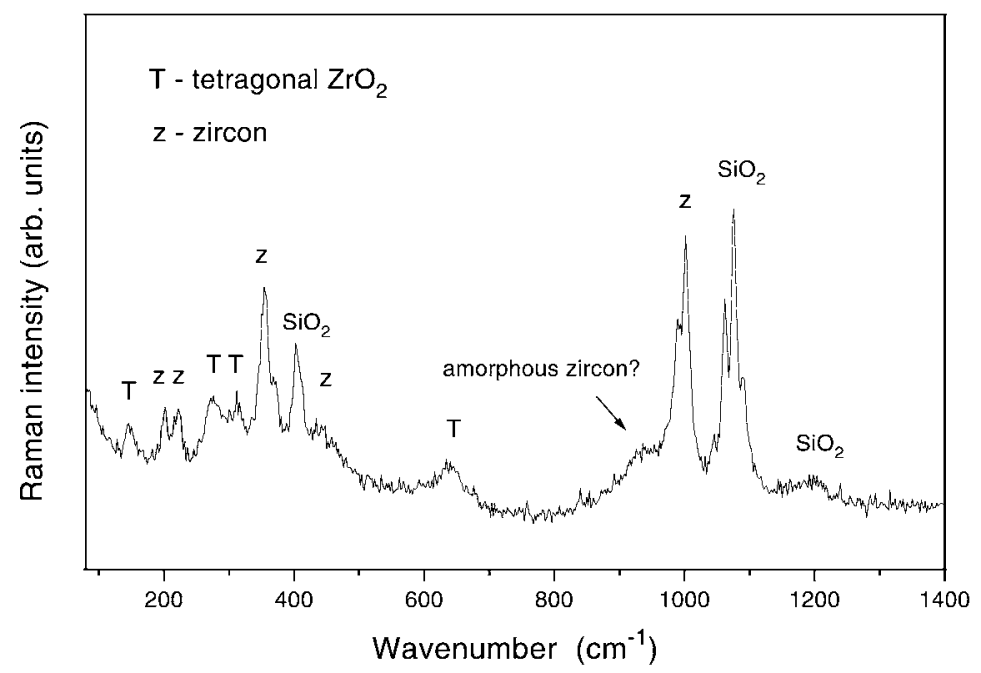

Figure 4. Raman spectrum of sample Cam1 between 80 and $1400 \mathrm{~cm}^{-1}$.

$\mathrm{ZrO}_{2}$ (figure 4). Zirconia has three polymorphs: the monoclinic, tetragonal and cubic structures (Smith and Newkirk 1965). In tetragonal $\mathrm{ZrO}_{2}$ with space group $\mathrm{D}_{4 \mathrm{~h}}^{15} / P 4_{2} / n m c$ $(Z=2)$, the predicted irreducible representations of optical phonons (for zero wave vector) are $\mathrm{A}_{1 g}(\mathrm{R})+2 \mathrm{~B}_{1 g}(\mathrm{R})+3 \mathrm{E}_{g}(\mathrm{R})+\mathrm{A}_{2 u}(\mathrm{IR})+2 \mathrm{E}_{u}(\mathrm{IR})$ and six phonon modes are expected to be Raman active while 18 and one Raman bands are expected for monoclinic and cubic $\mathrm{ZrO}_{4}$, respectively (Keramidas and White 1974, Anastassakis et al 1975, Kim and Hamaguchi 
1997). Kim et al (1993) have shown that tetragonal $\mathrm{ZrO}_{2}$ doped with 2 mol\% of $\mathrm{Y}_{2} \mathrm{O}_{3}$ shows characteristic bands at 145, 259,318, 462, 606 and $641 \mathrm{~cm}^{-1}$. The observed extra Raman bands in Cam1 are well consistent with those Raman bands of tetragonal $\mathrm{ZrO}_{2}$. Infrared powder and reflection spectra of Cam1, in fact, consist of damaged crystalline zircon, tetragonal $\mathrm{ZrO}_{2}$ and amorphous $\mathrm{SiO}_{2}$. No characteristic bands from cubic and monoclinic $\mathrm{ZrO}_{2}$ were observed in any samples.

\section{Discussion}

Our results show that radiation-damaged zircon samples give two signals: one from crystalline/distorted crystalline zircon and the other from amorphized zircon. The signal from the crystalline part of the sample shows a continuous decrease of the phonon frequencies and an increase of linewidths with increasing radiation dose.

The implication of the correlation between width and frequency of Raman $\mathrm{Si}-\mathrm{O}$ stretching and degree of radiation dose in zircon is that it may be used for the determination of the degree of damage from Raman peak parameters for partially damaged zircon samples. The existence of impurities in natural zircon may have an additional influence on peak profiles although this effect is expected to be small for our samples for the following reasons. Firstly, the samples have low levels of impurities. The most common impurities are Hf, $\mathrm{U}$ and Th. The Hf content is always less than $3 \mathrm{~mol} \%$. This is not sufficient to cause the observed phonon frequency shifts. Secondly, if Hf were the cause of a significant frequency shift in the spectrum of zircon one would expect to see, because of the difference of the ionic radius between $\mathrm{Zr}$ and $\mathrm{Hf}$ and complex host-lattice silicate interactions, a weak increase in frequency for the $\mathrm{Si}-\mathrm{O}$ stretching modes instead of the observed decrease (Nicola and Rutt 1974, Hoskin and Rodgers 1996). Thirdly, thermal treatment of a partially damaged sample (sample 4604, with dose of $3.5 \times 10^{18} \alpha$-events $\mathrm{g}^{-1}$ and less than $1.10 \mathrm{~mol} \%$ of $\mathrm{Hf}$ ) at high temperatures results in a recovery of the damaged structure of zircon as indicated by a band sharpening and an increase of phonon frequencies up to those of well crystallized samples (figure 5).

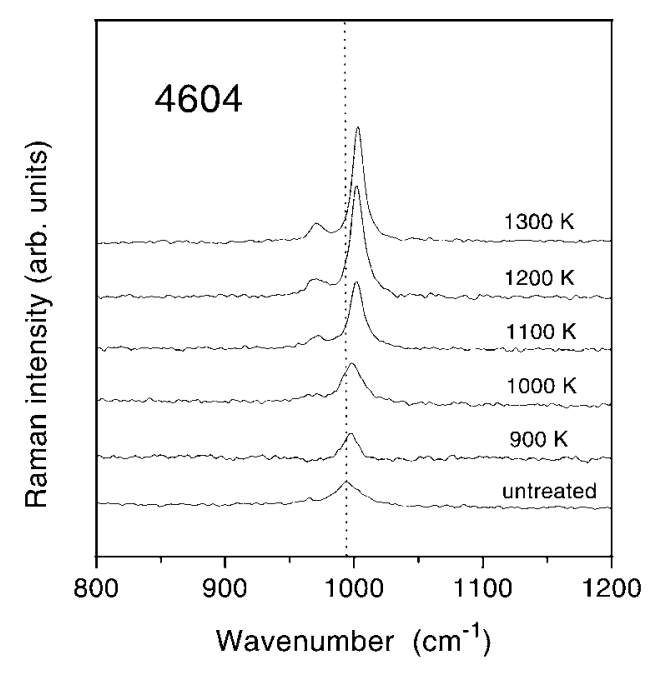

Figure 5. Spectra of zircon 4604 (dose $=3.5 \times 10^{18} \alpha$-events $\mathrm{g}^{-1}$ ) annealed at different temperatures for one hour. 
The dose dependence of the line shift of the $\mathrm{Si}-\mathrm{O}$ stretching and bending modes follows roughly the same behaviour as the increase of the unit cell volume of the crystalline part of the samples (Weber et al 1994). This observation probably implies that the Si-O bond strength decreases when the specific volume of the crystal increases. This may indicate that the bond distances increase or/and that the bond is depolarized by a rotation of the tetrahedra within the zircon structure. It clearly shows that the $\mathrm{SiO}_{4}$ tetrahedra are involved in the unit cell swelling and that they act as a significant part of the zircon structure rather than isolated molecular complexes.

The saturation of the mode softening at $\sim 3.5 \times 10^{18} \alpha$-events $\mathrm{g}^{-1}$ is understood in terms of the threshold behaviour discussed by Salje et al (1999). In this model, an upper limit for the local defect concentration exists in the crystalline part of the sample. If this defect concentration is exceeded by further damage the structure collapses and becomes amorphized. The characteristic dose $D_{s}$ for this effect is $\sim 3.5 \times 10^{18} \alpha$-events $\mathrm{g}^{-1}$ in zircon.

We finally discuss the question of whether increasing dose changes the structure of the amorphous component. Above $6.3 \times 10^{18} \alpha$-events $\mathrm{g}^{-1}$ the Raman spectra of the amorphous phase show no significant changes of their line profiles. The only visible change is in the intensity of the signals of the amorphous phase with no clear changes in band frequencies. This observation dose not rule out subtle changes of the local structure of amorphized zircon while large changes of the interconnection of the $\mathrm{SiO}_{4}$ tetrahedra can be ruled out. It also shows that no phase separation into a pure silica-type glass occurs unless the sample is annealed at high temperatures. The results of annealing experiments will be published in a forthcoming paper.

\section{Conclusion}

This study shows that two Raman signals coexist in radiation-damaged zircon due to an amorphous phase and a damaged crystalline phase. The signal from the crystalline volume shows spectral variations due to a softening of the crystal structure of zircon with increasing damage dose. A saturation of phonon frequencies was observed at dose of $\sim 3.5 \times 10^{18} \alpha$-events $\mathrm{g}^{-1}$, and this is explained by a percolation model proposed by Salje et al (1999). We observed that with increasing dose from $6.3 \times 10^{18} \alpha$-events $\mathrm{g}^{-1}$ the signals from the amorphous domain remain unchanged. This suggests that when a dose is higher than $6.3 \times 10^{18} \alpha$-events $\mathrm{g}^{-1}$ the structure of the amorphous domain is essentially identical. The results from this study also show that $\mathrm{ZrO}_{2}$ and $\mathrm{SiO}_{2}$ are not the principal products in metamict zircon.

\section{Acknowledgments}

The authors thank Mark Welch at the Natural History Museum (London, UK), Steve Laurie at the Sedgwick Museum (University of Cambridge, UK), Jochen Schlüter at the Mineralogisches Museum (Universität Hamburg, Germany) and Andreas Massanek at Freiberg University of Mining and Technology (Germany) for providing some of the samples used in this study. We are very grateful to $\mathbf{S} \mathbf{J}$ Reed for assistance with the electron microprobe analysis. This work would not have been possible without the carefully characterized samples resulting from the work of Takashi Murakami. Financial support from EU network ERB-FMRX-CT970108 is gratefully acknowledged. RCE gratefully acknowledges support for Basic Energy Sciences/DOE (DE-FG-02-97-ER45655). 


\section{References}

Aines R D and Rossman G R 1986 Am. Mineral. 711186

Anastassakis E, Papanicolaou B and Asher I M 1975 J. Phys. Chem. Solids 36667

Anderson B W 1962 Gemmologist 3119

Anderson E B, Burakov B E and Vasiliev V G 1993 Proc. Safe Waste '93 vol 2, p 29

Burakov B E 1993 Proc. Safe Waste '93 vol 2, p 19

Chakoumakos B C, Murakami T, Lumpkin G R and Ewing R C 1987 Science 2361556

Chakoumakos B C, Oliver W C, Lumpkin G R and Ewing R C 1991 Radiat. Eff. Defects Solids 118393

Dawson P, Hargreave M M and Wilkinson G F 1971 J. Phys. C: Solid State Phys. 4240

Ellsworth S, Navrotsky A and Ewing R C 1994 Phys. Chem. Mineral. 21140

Ewing R C 1994 Nucl. Instrum. Methods B 9122

1999 Proc. Natl Acad. Sci. USA 963432

Ewing R C, Lutze W and Weber W J 1995 J. Mater. Res. 10243

Farges F and Calas G 1991 Am. Mineral. 7660

Farnan I, Zhang M and Salje E K H 1999 J. Conf. Abs. 2634

Hazen R M and Finger L W 1979 Am. Mineral. 64157

Holland H D and Gottfried D 1955 Acta Crystallogr. 8291

Hoskin P W O and Rodgers K A 1996 Eur. J. Solid State Inorg. Chem. 331111

Keramidas V G and White W B 1974 J. Am. Ceram. Soc. 5722

Kim B K and Hamaguchi H O 1997 Phys. Status Solidi b 203557

Kim D J, Jung H J and Yang I S 1993 J. Am. Ceram. Soc. 762106

McLaren A C, Fitzgerald J D and Williams I S 1994 Geochim. Cosmochim. Acta 58993

Meldrum A, Boatner L A and Ewing R C 1998 Nature 39556

Meldrum A, Boatner L A, Zinkle S J, Wang S X, Wang L M and Ewing R C 1999a Can. Mineral. 37207

Meldrum A, Zinkle S J and Boatner L A 1999b Phys. Rev. B 593981

Murakami T, Chakoumakos B C, Ewing R C, Lumpkin G R and Weber W J 1991 Am. Mineral. 761510

Nasdala L, Irmer G and Wolf D 1995 Eur. J. Mineral. 7471

Nasdala L, Pidgeon R T and Wolf D 1996 Geochim. Cosmochim. Acta 601091

Nasdala L, Pidgeon R T, Wolf D and Irmer G 1998 Mineral. Petrol. 621

Nicola H H and Rutt H N 1974 J. Phys. C: Solid State Phys. 71381

Ríos S and Salje E K H 1999 J. Phys.: Condens. Matter 118947

Salje E K H, Chrosch J and Ewing R C 1999 Am. Mineral. 481107

Smith D K and Newkirk H K 1965 Acta Crystallogr. 18982

Stott V H and Hilliard A 1946 Mineral. Mag. 27198

Syme R W G, Lockwood D J and Kerr H J 1977 J. Phys. C: Solid State Phys. 101335

Vance E R 1975 Radiat. Eff. 241

Vance E R and Anderson B W 1972 Mineral. Mag. 38605

Wasilewski P J, Senftle F E, Vaz J E, Thorpe A N and Alexander C C 1973 Radiat. Eff. 17191

Weber W J 1993 J. Am. Ceram. Soc. 761729

Weber W J, Ewing R C, Angell C A, Arnold G W, Cormack A N, Delaye J M, Griscom D L, Hobbs L W, Navrotsky A, Price D L, Stoneham A M, Weinberg W C. 1997 J. Mater. Res. 121946

Weber W J, Ewing R C and Lutze W 1996 Mater. Res. Soc. Symp. Proc. vol 412 (Pittsburgh, PA: Materials Research Society) p 25

Weber W J, Ewing R C and Wang L M 1994 J. Mater. Res. 9688

Woodhead J A, Rossman G R and Silver L T 1991a Am. Mineral. 7674

Woodhead J A, Rossman G R and Thomas A P 1991b Am. Mineral. 761533

Yada K, Tanji T and Sunagawa I 1987 Phys. Chem. Mineral. 14197 